\title{
Critique of a scoping review of principles to guide interactions between population health researchers and the food industry
}

To the editor:

I read with interest the article by Cullerton et $\mathrm{al}^{1}$ that described the results of a scoping review to identify principles to guide interactions between population health researchers and the food industry. The purpose of this review, as stated by a team of co-authors at the University of Cambridge and University of Queensland in Australia, was to "systematically harvest from the literature, synthesize and analyze principles to help prevent or manage actual or perceived conflict of interest." The authors searched the peer-reviewed and grey literature and identified 56 principles extracted from 54 documents across two electronic databases between 1999 and 2017. They also consulted over 200 key informants related to the prevention and management of conflicts of interest between food industry actors and public health researchers.

This is a very important, timely, complex, and contentious topic for which empirical research suggests that there is no consensus across academics, funders, policymakers, and decision-makers worldwide, especially for engagement with the food and beverage industry. ${ }^{1}$ However, readers should cautiously consider four issues related to this scoping review when applying the findings to wider discussions about public- and private-sector engagement for nutrition and public health.

First, the authors aimed to clarify appropriate interactions between researchers and the food industry but did not clearly define "principles" in their methods. The Oxford University Press Living Dictionaries defines principle as "a fundamental truth or proposition that serves as the foundation for a system of belief or behavior or for a chain of reasoning." Principle may also be defined as "a rule or belief governing one's behavior" or pertain to "morally correct behavior and attitudes."

Second, the authors' search strategy included "public-private partnerships" although their research objective was narrowly focussed on principles within the context of securing funding and conducting research. The authors should have clarified that there are many reasons and motives underlying actor engagement through public-private partnerships, networks, alliances, coalitions, and multistakeholder platforms. Engagement may involve a range of activities including advocacy and lobbying, fundraising through cobranding activities such as cause marketing, designing and implementing policies and programmes, and potentially conducting

Prepared as a letter to the editor to submit to Obesity Reviews (IF = 8.483) https://onlinelibrary.wiley.com/page/journal/1467789x/homepage/forauthors.html research or evaluations to inform the effectiveness or impact of policies, programmes, legislation, laws, and regulations. ${ }^{3}$ Research or evaluations may be conducted in either academic, government, or NGO settings. A substantial amount of private-sector funding may be provided to researchers through corporate sponsorship and private philanthropy. ${ }^{4,5}$ Yet the search strategy did not include key terms related to "research," "evaluation," "sponsorship," "philanthropy," or "bias." Therefore, the authors may have missed important references to inform their results.

Third, the authors stated that "few documents recognized the diversity of types of interaction with industry or whether different strategies are required for different types of interactions." They recommend that a typology of interactions is needed to help researchers assess whether different guidance is needed for various interactions. Yet there is extensive published work on this topic that was not discussed by the authors. Kraak and Story ${ }^{3}$ and $\mathrm{Kraak}^{6}$ described guiding principles and a decision-making framework that government and non-governmental actors can use to decide whether and how to engage with private-sector entities for various activities (Table 1).

TABLE 1 Guiding principles and a decision-making framework for public-private partnerships to promote healthy food environments

\begin{tabular}{|c|c|}
\hline Guiding Principles & Decision-Making Steps or Actions \\
\hline $\begin{array}{l}\text { Public interest and } \\
\text { innovation }\end{array}$ & $\begin{array}{l}\text { Clarify goals and objectives that benefit } \\
\text { public health and the public good }\end{array}$ \\
\hline $\begin{array}{l}\text { Partner diversity and } \\
\text { compatibilities }\end{array}$ & $\begin{array}{l}\text { Conduct due diligence for compatibilities, } \\
\text { benefits, and risks }\end{array}$ \\
\hline $\begin{array}{l}\text { Pragmatic and } \\
\text { anticipatory planning }\end{array}$ & $\begin{array}{l}\text { Design a plan to manage tensions, biases, } \\
\text { and actual or perceived conflicts of } \\
\text { interest }\end{array}$ \\
\hline $\begin{array}{l}\text { Governance and } \\
\text { stewardship }\end{array}$ & $\begin{array}{l}\text { Develop a formal agreement to clarify the } \\
\text { terms of engagement including } \\
\text { governance structure, roles and } \\
\text { responsibilities, and stewardship of } \\
\text { resources }\end{array}$ \\
\hline $\begin{array}{l}\text { Accountability } \\
\text { (monitoring and } \\
\text { evaluation) }\end{array}$ & $\begin{array}{l}\text { Establish objective performance metrics and } \\
\text { design an independent body to take, } \\
\text { share, hold, and respond to the account }\end{array}$ \\
\hline $\begin{array}{l}\text { Communication, } \\
\text { continuity, or closure }\end{array}$ & $\begin{array}{l}\text { Communicate a consistent and accurate } \\
\text { story about the progress, achievements, } \\
\text { continuity, and closure to diverse } \\
\text { audiences }\end{array}$ \\
\hline
\end{tabular}

Sources: Kraak and Story ${ }^{3}$; Kraak et al. ${ }^{6}$ 
These tools were developed based on the principles of public interest, innovation, compatibility, stewardship, and accountability published by the Canadian Institute for Health ${ }^{7}$ in 2013 , which was not among the 54 documents cited in the scoping review. ${ }^{8}$

Moreover, the authors neglected to mention that the World Health Organization (WHO), a norm-setting institution for best practices among adhering Member States of 194 countries, had released draft documents and hosted an online consultation in September 2017 to solicit broad stakeholder feedback on industry engagement principles and decision-making tool to enable staff at government ministries and non-governmental organizations to decide whether and how to engage with private-sector bodies related to national programmes at the national level to safeguard against possible conflict of interest in nutrition programmes. ${ }^{9}$ The report titled, Approach for the prevention and management of conflicts of interest into the policy development and implementation of nutrition programmes at country level, was finalized in December 2017, and the typology and general principles ${ }^{10}$ were presented to the WHO Executive Board in January 2018.

The WHO typology includes six steps and a decision-making tool (Figure 1). ${ }^{11}$ Step 1 involves the researcher clarifying the rationale for engagement with a private-sector actor; step 2 is to profile and perform due diligence and risk assessment; step 3 is to balance the risks and benefits; step 4 involves risk management; step 5 entails monitoring, evaluation, and accountability; and step 6 involves transparency and communication. ${ }^{10}$ Cullerton et al recommended that public health researchers conduct a risk assessment as the first step and excluded any explicit language about a public health researcher assessing potential benefits to balance against the risks of engagement with industry actors. $^{3,10}$

- Finally, Cullerton et al acknowledge that researchers in various settings should be attentive to nonfinancial conflicts of interest, including career interests, networks that may bias funding and publication, and ideological conflicts that may arise from the personal or professional convictions about the political, economic, and spiritual aspects of their work. ${ }^{12}$ Policymakers need to provide greater leadership, and institutions must provide clarity and build a culture of accountability to support public health practitioners, researchers, and public-sector advisors and analysts in navigating a murky terrain of funding opportunities to identify, manage, and mitigate conflicts of interest. Institutional responses are needed to commercial

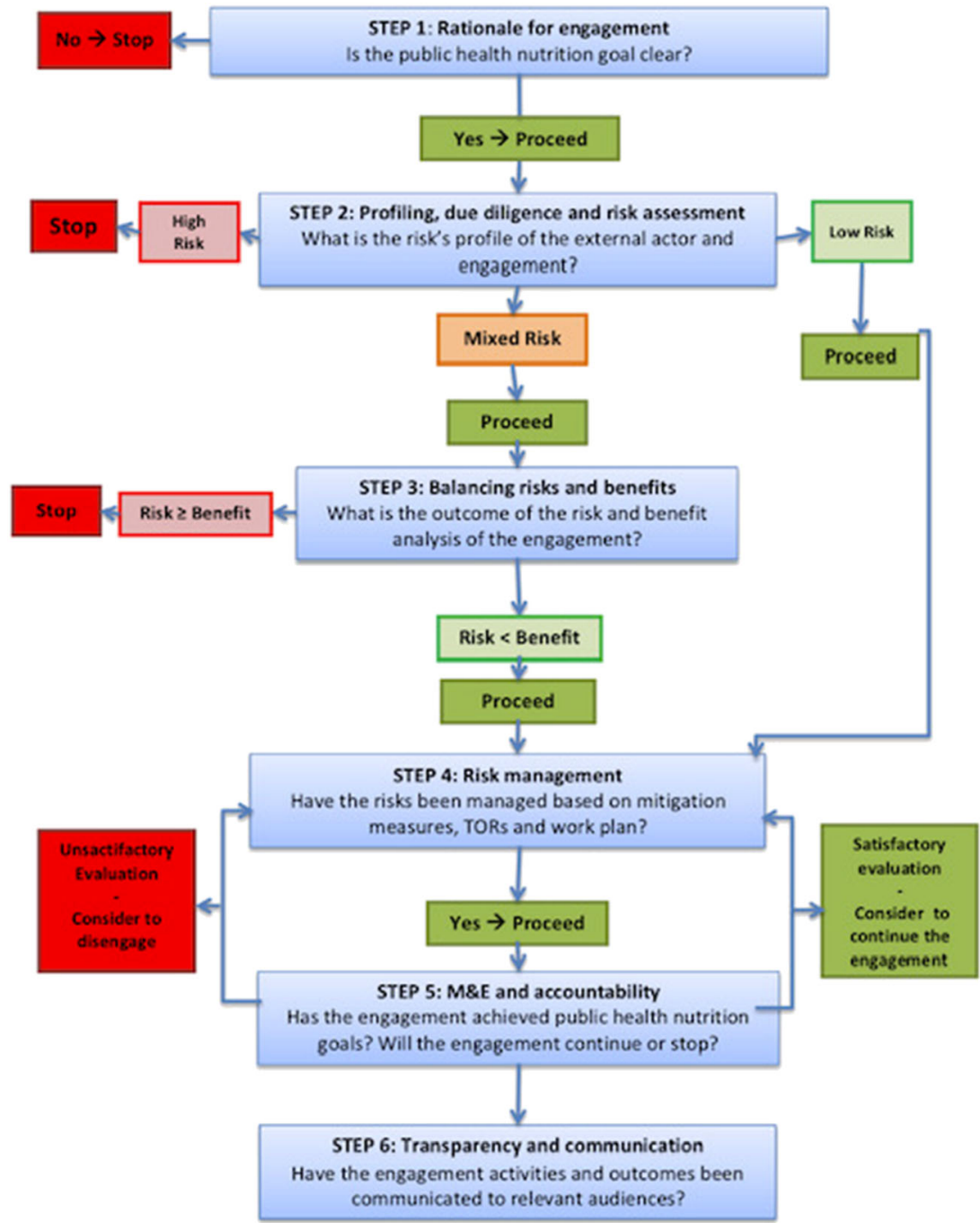

FIGURE 1 World Health Organization decision-making tool for non-state-actor engagement for public health and nutrition programmes

Source: WHO. ${ }^{11}$ [Colour figure can be viewed at wileyonlinelibrary.com] 
influences through disclosures, recusing oneself from important decisions, and prohibiting or penalizing financial ties between researchers and industry. ${ }^{13}$

\section{DISCLOSURES}

V.I.K has published extensively on the topic of public-private partnerships. She served as a consultant for the World Health Organization's Department of Nutrition and Health from 2015 to 2017 to assist in the development of the background paper and tools released in 2017 for Member States and other non-state actors for the prevention and management of conflicts of interest in the policy development and implementation of nutrition programmes at country level. She does not receive any funding from any commercial or privatesector firms or entities for research or consulting and has no conflicts of interest related to the content of this letter. Previous funding received for research related to this topic was from Health Canada and the Robert Wood Johnson Foundation.

\section{AUTHOR CONTRIBUTIONS}

Vivica I. Kraak conceptualized and drafted this letter for submission.

\section{ORCID}

Vivica I. Kraak (D) https://orcid.org/0000-0002-9303-5530

Vivica I. Kraak

Department of Human Nutrition, Foods, and Exercise, Virginia Tech, Blacksburg, Virginia

Correspondence Vivica I. Kraak, Assistant Professor of Food and Nutrition Policy, Department of Human Nutrition, Foods, and Exercise, Virginia Tech, 223 Wallace Hall, 295 West Campus Drive, Blacksburg, Virginia 24061, USA. Email: vivica51@vt.edu

\section{REFERENCES}

1. Collin J, Hill SE, Kandlik Eltanani M, Plotnikova E, Ralston R, Smith KE. Can public health reconcile profits and pandemics? An analysis of attitudes to commercial sector engagement in health policy and research. PLoS ONE. 2017;12(9):e0182612. https://doi.org/10.1371/journal. pone. 0182612

2. Oxford University Press. English Oxford Living Dictionaries. Principle. 2019. [WWW document]. https://en.oxforddictionaries.com/definition/principle (accessed April 2019).
3. Kraak VI, Story M. Guiding principles and a decision-making framework for stakeholders pursuing healthy food environments. Health Aff. 2015;34(11):1972-1978

4. Aaron DG, Siegel MB. Sponsorship of national health organizations by two major soda companies. Am J Prev Med. 2017;52(1):20-30. https:// doi.org/10.1016/j.amepre.2016.08.010

5. Organisation for Economic Co-operation and Development. Private philanthropy funding guidelines. n.d. [WWW document]. http://www. oecd.org/site/netfwd/ENG\%20-\%20Guidelines\%20for\%20Effective\% 20Philanthropic\%20Engagement\%20country\%20pilots.pdf laccessed April 2019).

6. Kraak VI, Health Canada, the Ontario Ministry of Health and Long Term Care, and the Healthy People and Communities Steering Committee's Multi-Sectoral Partnerships Task Group. Public health and food and beverage industry engagement: a tool to guide partnership opportunities and challenges. Ontario, Canada, May 2014. [WWW document]. https://www.paho.org/hq/dmdocuments/2015/ppptg-guide.PDF (accessed April 2019).

7. Canadian Institute for Health Research. Canadian Institutes of Health Research (CIHR) ethics framework for partnerships with the private sector, 2011 updated March 2013. [WWW document]. http://www. cihr-irsc.gc.ca/e/34746.html (accessed April 2019).

8. Cullerton K, Adams J, Forouhi N, Francis O, White M. What principles should guide interactions between population health researchers and the food industry? Systematic scoping review of peer-reviewed and grey literature. Obes Rev. 2019;20(8):1073-1084. https://doi.org/ 10.1111/obr.12851

9. World Health Organization. Safeguarding against possible conflicts of interest in nutrition programmes: approach for the prevention and management of conflicts of interest in the policy development and implementation of nutrition programmes at country level. Feedback on the WHO consultation. 2017. [WWW document]. https://www. who.int/nutrition/consultation-doi/comments/en/ (accessed April 2019).

10. World Health Organization. Safeguarding against possible conflicts of interest in nutrition programmes. Executive Board. 142nd session. Provisional agenda item 4.6. EB142/23. 4 December 2017. http://apps. who.int/gb/ebwha/pdf_files/EB142/B142_23-en.pdf?ua=1 (accessed April 2019).

11. World Health Organization. Decision-making process and tool. Geneva: WHO; 4 December 2017. [WWW document]. https://www.who.int/ nutrition/consultation-doi/nutrition-tool.pdf?ua=1 (accessed April 2019).

12. Galea S. A typology of nonfinancial conflict in population health research. Am J Public Health. 2018;108(5):631-632. https://doi.org/ 10.2105/AJPH.2018.304333

13. Bero LA, Grundy Q. Not all influences on science are conflicts of interest. Am J Public Health. 2018;108(5):632-633. https://doi.org/ 10.2105/AJPH.2018.304334 